\title{
Las nuevas dinámicas rurales en las zonas de reserva campesina en Colombia ${ }^{1}$
}

\section{THE NEW RURAL DYNAMICS IN PEASANTS RESERVE ZONES IN COLOMBIA}

\author{
A NOVA DINÂMICA RURAL NAS ÁREAS DE RESERVA CAMPONESA \\ NA COLÔMBIA
}

Para citar este artículo: Tocancipá Falla, J. y Ramírez Castrillón, C. A. (2018). Las nuevas dinámicas rurales en las zonas de reserva campesina en Colombia. Perspectiva Geográfica, 23(1), 31-52. doi: 10.19053/01233769.5796
JAIRO Tocancipá Falla² CRISTIAN ARNOLDO Ramírez Castrillón ${ }^{3}$
Recibido:

26 de abril de 2017

Evaluación:

20 de octubre de 2017

Aprobación:

15 de marzo de 2018

\section{Resumen}

En este artículo se examinan las nuevas dinámicas de configuración y ordenamiento del espacio rural desde la perspectiva de la teoría territorial, las estrategias de vida rurales y los nuevos estilos adaptativos. Se examinan dos estudios de caso, uno formal y otro de facto, donde se revelan diversas estrategias de sobrevivencia, organización y resistencia frente a las políticas del Estado. Así mismo, se plantean algunas ideas

1 Este documento hace parte del proyecto de tesis doctoral denominado "Del Pato al Quimbo", de la lucha por la tierra a la construcción territorial. El caso de las zonas de reserva campesina de Caquetá y Huila. El proyecto se realiza en el marco del programa de Doctorado en Estudios Territoriales (DET) que actualmente imparte el Instituto de Investigaciones en Ciencias Sociales y Humanas (ICSH) de la Universidad de Caldas.

2 Postdoctorado en Antropología de la Universidad Johns Hopkins, Ph. D. en Antropología Social de la Universidad de Cambridge. Docente investigador de la Universidad del Cauca, director del Grupo de Estudios Sociales Comparativos. Director de la tesis "Del Pato al Quimbo", de la lucha por la tierra a la construcción territorial. El caso de las zonas de reserva campesina de Caquetá y Huila, presentada en el marco del programa de Doctorado en Estudios Territoriales de la Universidad de Caldas. Correo electrónico: jtocancipa@unicauca.edu.co.

3 Magíster en Política y Gobierno de la Facultad Latinoamericana de Ciencias Sociales Flacso-Chile; doctorando en Estudios Territoriales de la Universidad de Caldas (Grupo de Investigación Territorialidades). Docente investigador de la Universidad Surcolombiana (Grupo de Investigación Iguaque). Correo electrónico: cristian.ramirez@usco.edu.co. 
preliminares sobre los desafíos en torno a la propiedad, la tenencia, el uso, el manejo, la apropiación y la gestión de la tierra para el diseño y la implementación de políticas públicas de ordenamiento territorial en Colombia.

Palabras clave: campesinos, configuración territorial, identidad, territorio, reserva campesina.

\section{Abstract}

In this paper we examine the new dynamics of configuration and ordering of rural space will be studied from the perspective of territorial theory, rural life strategies and the new adaptive styles. Different surviving strategies, organizations and resistance movement against the State policies are revealed through two case studies, one formal and other de facto. Some preliminary ideas are presented on the challenges of land ownership, use, management and management in the design and implementation of public land management policies.

Keywords: identity, peasant, territorial configuration, peasants reserve, territory.

\section{Resumo}

Neste artigo são analisadas as novas dinâmicas de configuração e ordenação do espaço rural a partir da perspectiva da teoria territorial, estratégias de vida rural e novos estilos adaptativos. Dois estudos de caso são examinados, um formal e o outro de fato, revelando várias estratégias de sobrevivência, organização e resistência às políticas do Estado. São apresentadas algumas idéias preliminares sobre os desafios que giram em torno da propriedade, posse, uso, gestão, apropriação e gestão da terra, no projeto e implementação de políticas públicas de ordem territorial na Colômbia.

Palavras chave: identidade, camponês, configuração territorial, reserva de camponeses, território. 


\section{Introducción}

Las zonas de reserva campesina (en adelante, ZRC) son figuras jurídicas creadas para favorecer el desarrollo rural y la reforma agraria en Colombia. Básicamente, son consideradas como áreas geográficas que tienen en cuenta características ambientales, agroecológicas y socioeconómicas espacializadas para el ordenamiento territorial, social y cultural de la propiedad, para la estabilización y la consolidación de la economía campesina (Machado, 1999). Luego de largas manifestaciones y conflictos rurales en los años veinte, la radicalización de las demandas campesinas desbordó las haciendas cafeteras hasta la expedición de la Ley 200 de $1936^{4}$. Así fue tomando forma la figura de la ZRC, y luego de los fenómenos migratorios que acentuaron el establecimiento de pequeñas colonias agrícolas se fue consolidando desde los años cincuenta y sesenta. En los noventa, las ZRC fueron delimitadas y constituidas por la junta directiva del Instituto Colombiano de Reforma Agraria (Incora) ${ }^{5}$

4 A esta ley le antecedieron varias que favorecían las comunidades de colonos, como el Código Fiscal de 1912, la Ley 71 de 1917, Ley 85 de 1920, Ley 114 de 1922, Ley 100 de 1923, Ley 47, Ley 52 y Ley 74 de 1926, especialmente las leyes promotoras de los procesos de colonización que se retoman en el Decreto 839 del 8 de mayo de 1928, por el cual se fomenta la colonización de tierras baldías; sin embargo, se dice que la figura de zona de reserva toma forma con la expedición del Decreto 1110 de 1928, mediante el cual se definen algunos límites y linderos, y se asignan a los departamentos cantidades importantes de terrenos baldíos para fomentar la ocupación de esas tierras.

5 Ver el Decreto 1777/96 y el Acuerdo 024/1996 de la Junta Directiva del Incora. En el 2003 se liquida el Incora mediante Decreto 1292 y se expide el Decreto 1300 de la Presidencia de la República, a través del cual se crea el Instituto Colombiano de Desarrollo Rural (Incoder), promotor de la reactivación de la figura de las ZRC en el Valle del río Cimitarra en 2011 y de las demás iniciativas presentadas en Barrancabermeja en el año 2010 durante el Primer Encuentro Nacional de ZRC. En el 2015 se firmó el Decreto 2365 de la Presidencia de la República, por medio del cual se suprime y liquida el Instituto Colombiano de Desarrollo Rural (Incoder). En su reemplazo, ese año se creó la Agencia de Desarrollo rural (ADR) y la Agencia como figura e instrumento político y jurídico que contribuyera a materializar los intentos de reforma agraria a nivel local, regional y nacional, en términos de afectar la estructura de la tenencia de la tierra, disminuir el latifundio, ampliar la frontera agrícola y asegurarle a los campesinos la propiedad de la tierra, para lo cual se define la unidad agrícola familiar (UAF) como garantía y medio de sobrevivencia, producción y reproducción social de las familias campesinas (Ley 160 de 1994; Ocampo, 2014; Forero, 2013; Estrada, Ferro Medina, Huffington y Herrera, 2013; Osejo, 2013). A mayo de 2017, en el país se habían constituido seis ZRC: Pato-Balsillas, en el departamento del Caquetá (1997), Calamar, en el departamento del Guaviare (1997), Sur de Bolívar, en el departamento de Bolívar (1999), La Perla Amazónica, en Putumayo (2000), Cabrera, en el departamento de Cundinamarca (2000), y Valle del Río Cimitarra, en los departamentos de Antioquia y Bolívar (2002). Igualmente, existen siete proyectos de creación de nuevas ZRC en otras partes del país y siete constituidas de hecho o de facto, la mayoría en el departamento del Cauca y una de ellas en el departamento del Huila, asociada con el proyecto hidroeléctrico de la represa de El Quimbo que examinaremos más adelante. En total, para la fecha señalada, entre ZRC constituidas, en proyecto y de facto, en Colombia existen 21 iniciativas de este orden (Instituto Colombiano de Desarrollo Rural [Incoder], Instituto Latinoamericano para una Sociedad y un Derecho Alternativo [ILSA] y Sindicato de Pequeños Agricultores de Cundinamarca [Sinpeagricun], 2012).

Existen varios enfoques y caracterizaciones para el análisis de las ZRC, que van desde la nueva

Nacional de Tierras (ANT) como autoridad en materia de ZRC y las nuevas iniciativas. 
ruralidad, pasando por el desarrollo territorial rural (DTR) hasta las estrategias centradas en la vida rural y el actor social ${ }^{6}$. La primera, más que un enfoque, es una caracterización que se refiere a situaciones donde "las características que tradicionalmente han definido la ruralidad — baja densidad, predominio de actividades primarias y una vida cultural solidaria - son insuficientes para describir la situación actual de las áreas rurales en la mayor parte de América Latina", lo que se traduce en un proceso de "descampesinización" del sector rural y su inserción en la dinámica agroalimentaria mundial (Kay, 2007, p. 29; ver también Llambí y Pérez, 2007; Giarracca, 1993). El desarrollo territorial rural (DTR), visto más como un enfoque aplicado, es considerado como "una iniciativa de investigación aplicada para impulsar un proceso de transformación productiva e institucional en un espacio determinado" con el fin de reducir la pobreza rural (Schejtman y Berdegué, 2004, p. 4). Este enfoque es convergente con la idea del desarrollo rural como articulador del territorio rural y los mercados, con base en los criterios de competitividad local, institucionalidad incluyente (centrada en generar acuerdos entre actores y, con ello, activos y recursos) y una visión territorial más regional para la superación de la pobreza rural en relación con el espacio-tiempo (Moser, 1998; Ruiz y Delgado, 2008).

En esta perspectiva, el DTR propone las coaliciones sociales e innovadoras, que son aquellas dinámicas que se construyen a lo largo del tiempo y que tienen efectivamente un poder de incidencia en el territorio, que no necesariamente son expresiones explícitas

6 Tanto las caracterizaciones como los enfoques son cruciales para el análisis de una situación dada. No creemos que se trate de disyuntivas o elecciones, sino de posibilidades complementarias. de estas dinámicas de poder, que pueden ser básicas o implícitas, pero que tienen la suficiente fuerza para incidir en lo que se hace en el territorio y en la dinámica nacional, en el sentido de proveer recursos y de una nueva política (Berdegué et. al., 2011). El resultado es que se presenta una composición de base amplia y de coaliciones poderosas que sugieren una discusión de un proyecto territorial que se vuelve importante. Este enfoque puede ser de utilidad para entender la eventual orientación neoliberal por la que transitarán las ZRC, incluida una posibilidad de consolidación territorial con proyectos microarticulados con el mercado, condición ya observada en varios contextos en el país. Finalmente, tenemos el enfoque de las estrategias de vida rural que surgió a finales de la década de los ochenta e inicios de los noventa con el propósito de superar la visión economicista de la vida y como contribución para la superación de la pobreza rural:

El énfasis principal de los estudios que adoptan el enfoque de las estrategias de vida y que tratan de superar la dualidad de estructura y agencia en la sociología, ha sido más por el lado del actor antes que por el lado de las estructuras, al igual que en los análisis de Long en los cuales trata de combinar elementos de la sociología orientada al actor (Actor-oriented Sociology) con elementos de enfoques estructuralistas tales como la teoría de la dependencia y del sistema mundial (World System) [...] como por ejemplo a través del concepto de 'estructuración' ('Structuration') de Giddens (1998) (Kay, 2007, p. 33).

En la perspectiva de la sociología orientada al actor también se valoran los conocimientos de 
los campesinos y la interpretación que ellos hacen de la realidad (Long y Long, 1992). Un énfasis importante en este enfoque es el planteado por Cristóbal Kay (2007):

El enfoque de las estrategias de vida parte de la premisa de que 'los pobres poseen antes de lo que no poseen'; es decir, se parte de los activos (assets) con que la gente cuenta, y entiende a las estrategias de vida como las formas en que la gente logra el acceso a dichos activos y los combina de una manera particular en el proceso productivo (uso, transformación y reproducción de los variados capitales) transformándolos en medios de vida. Se toman en consideración una gama variada de activos: el capital humano (personas con sus diferentes niveles de educación, destrezas y salud, etc.), el capital social (redes familiares, comunitarias y sociales, etc.), el capital natural (tierra, agua, bosques, etc.), el capital físico (infraestructura, emplazamientos, maquinaria, animales, semillas, etc.), el capital financiero (Comercio, Consumo, Acumulación) y el capital cultural (Historia, Patrimonio) (p. 31).

Nuestro examen de las ZRC se enmarca en este último enfoque; específicamente, buscamos documentar a partir de dos experiencias, una formada institucionalmente y otra en proceso, de qué manera se materializan estas estrategias de vida rural en el marco jurídico que el Estado ha venido agenciando en años recientes. Como resultado, nos interesa igualmente establecer cómo dichos espacios recién creados aluden a formas organizativas y de comportamiento de las comunidades que habitan y caracterizan cada ZRC. Consideramos que abordar las dinámicas de configuración territorial en el sector rural desde la perspectiva de las estrategias de vida rural nos permite aproximarnos a la potenciación de sus capacidades y recursos, y a su propia visión de mundo. Es invertir la mirada: en lugar de acercarnos a la visión, se trata de tomar las estrategias para validar las capacidades y recursos de vida rural desde un enfoque multidimensional. Más allá de la consideración simple y poco elaborada sobre lo rural en la cual se asume el espacio como algo absoluto y con existencia propia, se busca analizar el espacio de las ZRC como un conjunto de relaciones sociales que hacen parte de esas estrategias que buscan cierta autonomía en un mundo cada vez más agresivo; es decir, se trata de acercarnos a los actores que hacen posible la ZRC como un sujeto-objeto socialmente construido, socialmente percibido y valorado en su actuar y prospectiva.

En este ámbito también se encuentran las dinámicas de las interrelaciones del marco legal que les da vida y los procesos de construcción de prácticas, discursos, estrategias de vida e identidades sociales que se fundan en las relaciones que establecen con otras estructuras y actores. Para lograr este examen se realizó una revisión bibliográfica que, si bien no es exhaustiva, está actualizada en cuanto a los antecedentes teóricos y temáticos sobre las cuestiones rurales desde la geografía económica, la sociología, la antropología y la economía. Esta información se contrastó con la obtenida en dos ZRC: El Pato-Balsillas, en el departamento del Caquetá, y la asociada a la represa de El Quimbo, en el departamento del Huila. El desarrollo de este planteamiento se efectúa en tres secciones: la primera parte es conceptual y en ella abordamos las territorialidades campesinas, las ZRC y el ordenamiento territorial para luego, en una segunda sección, enmarcar los dos estudios 
de caso que revelan las estrategias de vida rural en las dinámicas territoriales que hasta el momento se han reportado; finalmente, ofrecemos algunas conclusiones y nuevos interrogantes para posteriores investigaciones.

\section{Territorialidades campesinas, ZRC y ordenamiento territorial}

Existen dos dimensiones claves para discutir: de un lado se tienen los enfoques teóricos del territorio y sus configuraciones, más allá de la condición humana, y de otro está la parte normativa, que en este caso equiparamos con el ordenamiento territorial que materializa el ejercicio del Estado a través del mundo jurídico. En el primer caso, debemos destacar que los estudios sobre el territorio, las territorializaciones y las territorialidades campesinas han tomado fuerza durante los últimos años y son fuente de conflictos de reivindicación y de proyección. Tal como indica Silva (2016), "el concepto de territorio lleva implícitamente las nociones de apropiación, ejercicio de dominio y control de una porción de la superficie terrestre, pero también contiene las ideas de pertenencia y de proyectos que una sociedad desarrolla en un espacio dado" (p. 4).

Decía Ferdinand de Saussure (2003) que "el punto de vista crea el objeto", y nuestro punto de vista es que las ZRC deben ser estudiadas in situ, en su singularidad, a partir de sus propias dinámicas y desde el ejercicio que desempeñan los actores en lo territorial; es decir, entender cómo se produce el territorio en ellas y si tal producción se puede leer como la emergencia de una nueva situación rural que nos permita entender mejor los procesos campesinos de la actualidad (Zambrano, 2013).
Para efectos del presente artículo, las miradas sobre lo territorial y lo local tienen que estar mediadas por la relación entre el espacio (como lo físicamente dado), el territorio como espacio construido, la ZRC (como territorio producido) y los procesos regionales sociales, económicos y políticos que agencian los actores, en este caso, los campesinos. No se puede leer lo local ni lo territorial si no se tiene en cuenta lo geográficamente dado, lo socialmente producido y lo políticamente construido. Dentro de estos últimos factores, lo decisivo es, desde luego, la capacidad de gestión, la producción, la construcción y la distribución de los poderes, en tanto que lo geográficamente dado es esa parte física preexistente que aún no ha sido intervenida por la acción del hombre y que sólo cobra sentido cuando él actúa delimitando, emplazando y transformando el paisaje, construyendo imaginarios e identidades (territorialidades) sobre este. Ahora bien, esta producción del paisaje, como la llaman los geógrafos, como historias sedimentadas en el suelo, proporciona información que proviene de dos memorias: la memoria de la naturaleza y la memoria del tiempo de los hombres; esos paisajes son tanto una marca de la acción humana como una matriz en la que esta se generan (Dollfus, 1991; Gurevich, 2005). Aquí no nos quedamos solamente en la "antropologización" del territorio y de sus componentes naturales, a los cuales también se les concede "agency" (Giddens, 1998). Desde esta perspectiva, las posibilidades son diversas. Así, en términos de Silva (2016), "el espacio es apropiado, dominado, gestionado y controlado, generándose así territorios múltiples” (p. 4).

En ese sentido, existe un sinnúmero de espacios producidos, desde los supranacionales hasta los locales, cada uno de los cuales responde a modos de 
organización del capital y de los poderes representados, que se rigen por las finalidades perseguidas (Lipietz, 1979). Como lo señala Dollfus (1991), refiriéndose a la variabilidad de los espacios producidos, "si nos limitamos a la época contemporánea, existe el espacio limitado por los Estados, divididos en circunscripciones administrativas para poder encuadrar a las poblaciones y ejercer sus atribuciones de soberanía" (p. 26); también existe el espacio gestionado y construido por las comunidades a partir de su diario vivir; por otro lado, están los espacios organizados y gobernados por las ciudades, en los que dominan las relaciones centro-periferia y los flujos que los alimentan. Así, "existe el espacio de la empresa en la que desarrollan sus actividades los productores, trátese de mineros, agricultores, ganaderos o industriales" (Lipietz, 1979, p. 28). En consecuencia, el análisis de la variabilidad y la organización de estos espacios producidos depende de la naturaleza, la composición y la disposición de los distintos actores sociales y políticos que lo configuran, y que se traduce en la capacidad para construir el territorio (Bozzano, 2004). En palabras de Linck (2000), se trata de "la capacidad de renovación y movilización de recursos propios para responder a las nuevas expectativas que se manifiestan en torno de las nuevas funciones de los espacios rurales" (p. 2).

Según el enfoque socioespacial de Linck y Caron (1999, p. 16), el espacio se considera como algo intrínseco a cualquier construcción social y hace hincapié en el estudio de los procesos de producción y las representaciones territoriales. El territorio es, entonces, un producto y una dimensión de las sociedades humanas, un conjunto apropiado, explotado, recorrido, habitado y administrado según el juego y el dimensionamiento de los diferentes actores que lo producen (Santos, 1996; Nates-Cruz,
2007; Zambrano, 2010). Para Diego Silva (2016), "a este proceso de apropiación y de construcción sociopolítica por parte de actores se le denomina como territorialización, de carácter dinámico y conflictivo. Es igualmente importante destacar el elemento de la pertenencia. La fuerza que está implícita en los procesos de conformación territorial o territorialización estriba en la necesidad de configurar pertenencias colectivas e individuales mediante proyectos propios" (p. 4). Según Raffestin (2011), "la territorialidad compromete tres aspectos que se entrelazan: a) El sentido de identidad espacial, b) el sentido de exclusividad y c) la compartimentación de la interacción humana en el espacio" (p. 113).

Como se indicó, desde el punto de vista social existen variaciones en la construcción de ese espacio, que presenta ciertas "rugosidades" que dan origen a las distintas manifestaciones y diferenciaciones regionales, las cuales conducen a sucesivas reorganizaciones del espacio. "Rugosidades" que bien pueden estar asociadas, a su vez, a las "desigualdades de poder que existen entre las instituciones, las empresas y los hombres" (Santos, 1990, p. 178), o bien a las intencionalidades y disposiciones de los mismos actores, como ocurre con las ZRC. Obviamente, cuando se habla de desarrollo regional o de ordenamiento territorial se habla de reorganización del espacio, pero la mayoría de las veces se deja de telón de fondo el problema del poder. En este sentido, existe una serie de factores de poder regional y local que han entorpecido, para el caso colombiano, el funcionamiento a plenitud de los mecanismos e instrumentos democráticos de producción del espacio: la exclusión espacial, social y política, el clientelismo y, por supuesto, el conflicto armado son algunos ejemplos. La ocupación espacial histórica del territorio, los procesos de colonización agraria y de asentamientos pobla- 
cionales, como en el caso de la ZRC de El Pato, la destrucción ambiental, la permisividad estatal y el despojo "legal", como en el caso de la ZRC de El Quimbo, han generado una alta concentración de la tierra, constituyen elementos críticos de la realidad agraria y rural y son generadores de violencia (Baribbi y Spijkers, 2011).

En el país, la actual disputa entre los distintos actores armados por los espacios de poder, que pasa por el control de territorios, es una prueba de que la dimensión regional y local ha estado presente desde los orígenes mismos del conflicto bélico, particularmente acentuado a partir de la crisis del modelo centralista de Estado y de los inicios de los procesos de descentralización durante los ochenta (González, 1992). Se crearon así no solo nuevos espacios de guerra, sino que se empezaron a regionalizar y localizar las propias estrategias políticas contempladas dentro del proyecto político nacional, tanto de la insurgencia como de la contrainsurgencia estatal y paraestatal. Así, la lucha por el control político nacional pasa por la construcción de poderes regionales y locales (López, 2013). Sin embargo, el hecho de que la confrontación armada de por sí tienda a erosionar el campo de construcción política del territorio, al subordinarlo exclusivamente a los resultados militares y al ejercicio de la coerción, introduce severas restricciones a sus aspiraciones de construcción del poder político local (González, 2004), en especial por parte de otros actores que no están necesariamente vinculados al conflicto armado. De hecho, la construcción del poder va más allá del simple control militar del territorio y muchas veces se evidencia en la activación de mecanismos de participación y decisión comunitaria y ciudadana, que se orientan a la construcción de procesos de legitimación social y política.
Una aproximación a la dimensión espacial y sus diversas manifestaciones nos introduce de plano en los procesos de diferenciación territorial y su relación con el desarrollo y puesta en marcha de las distintas estrategias políticas de construcción del territorio por parte de diferentes actores sociales y políticos (López, 2013; Centro Nacional de Memoria Histórica, 2014).

Pero la construcción no es necesariamente estable y está sujeta a presiones constantes, hecho que genera las nuevas dinámicas territoriales. Según Linck (2001), "la difusión de nuevos patrones de consumo y hábitos de vida, la megapolización de los sistemas urbanos, los avances tecnológicos y de las telecomunicaciones y la creciente movilidad de la población han modificado radicalmente los patrones de organización del territorio rural" (p. 1), pero con ello también se ve afectado el perfil sociológico y cultural de la población (Dirven, 2004; Harvey, 2003; Massey, 2007; Sassen, 2015). Tal como señala Bauman (2008), "la diversificación de campos de acción contenidos en la 'modernidad' han de caracterizarse por una desorganización constante de los ritmos temporales y espaciales que estimulan prácticas culturales y sociopolíticas marcadas por una creciente fragmentación, discontinuidad y yuxtaposición de lógicas contingentes de sentido" (p. 78). La transformación del perfil sociológico de la población rural y la consolidación de nuevas demandas sociales hacia el campo han impulsado el auge de nuevas funciones de los espacios rurales. En este orden, conviene examinar el caso colombiano respecto a las políticas orientadas a incidir en el ámbito territorial.

Aquí destacamos, en segundo lugar, el tema del ordenamiento territorial. En Colombia, la legislación sobre las ZRC define el concepto de ordenamiento ambiental territorial (OAT) como criterio regulador (Ministerio del Medio Ambiente, 1998). Sin embar- 
go, el concepto, como norma general, no puede dar cuenta de las variaciones territoriales arriba discutidas. En cierto modo, la normatividad es contextual e imprecisa, y, por lo tanto, está sujeta a variadas interpretaciones, tanto por parte del Estado como de los demás actores territoriales (Fals Borda, 1969). Por esto mismo su influencia como determinante del ordenamiento también es variada (Ruiz, 2015).

En relación con la visión del ordenamiento ambiental territorial por parte del campesinado, en el Segundo Congreso Colombiano de Áreas Protegidas llevado a cabo en Bogotá, en julio de 2014, la Asociación Nacional de Zonas de Reserva Campesina (Anzorc) presentó la ponencia Ordenamiento ambiental, derechos campesinos: una ruta para la construcción de paz, tres elementos fundamentales para que las áreas protegidas sean zonas de vida y para la paz, donde se explicitaron tres aspectos importantes para nuestro propósito. Primero, el reconocimiento al campesinado como sujeto político de derechos; segundo, el reordenamiento territorial ambiental del país; y tercero, el reconocimiento al campesinado como sujetos de conservación (Anzorc, 2014); este último aspecto convergente con la idea del "buen salvaje" mencionada por varios autores (Ulloa, 2006). Una tarea importante sería indagar hasta qué punto estos elementos se están dando en las prácticas asociadas con las ZRC (Forero, 2013; Reyes, 2016). En palabras de López (2013), las ZRC pueden pensarse como una posibilidad territorial "que ofrece la acción local de pobladores, campesinos e indígenas en la construcción de alternativas innovadoras con base en la cooperación, la solidaridad y otros medios pacíficos para la transformación de los conflictos" (p. 24) con potenciales creativos.

Es en este ámbito que deseamos examinar dos experiencias de configuraciones territoriales enmarcadas Vol. 23 N. ${ }^{\circ} 1$ enero - junio de 2018 pp. 31-52 en las ZRC y que permiten apreciar las dinámicas sociales y políticas que los actores sociales, en este caso, los campesinos, desarrollan como estrategias de cambio y adaptación a las transformaciones globales que tratan de incidir en el mundo rural.

\section{Configuraciones territoriales y estrategias de vida rural}

A partir de lo anterior, deseamos documentar brevemente dos experiencias de ZRC contrastantes: una de ellas representa una de las primeras experiencias de este orden (Pato-Balsillas en el departamento del Caquetá), y la otra se refiere al impacto que genera una represa (El Quimbo en el departamento del Huila), y que motivó una acción política organizada que busca restablecer los derechos territoriales y de sobrevivencia vulnerados.

La ZRC de E1 Pato-Balsillas se encuentra ubicada a dos horas de Neiva, capital del departamento del Huila, y ha sido el resultado del desplazamiento y la violencia armada emanada del bipartidismo político de los años sesenta y de la Ley de Reforma Agraria, mediada por procesos de colonización campesina y del establecimiento de comunidades de parentesco, compadrazgo y vecindad de campesinos sin tierra que actualmente se enfrentan, en competencia desventajosa, con intereses de proyectos agroindustriales, agrocomerciales y de ganadería extensiva, y resisten por su permanencia en un territorio compartido con actores armados (Carrillo González, 2016). Esta ZRC se constituyó mediante la Resolución 055 del 18 de diciembre de 1997, con una extensión de 88.401 hectáreas que favorecen una población de 7.500 campesinos distribuidos en 27 veredas ubicadas en el municipio de San Vicente del Caguán, al nororiente del departamento del Caquetá (Anzorc, 2014). 


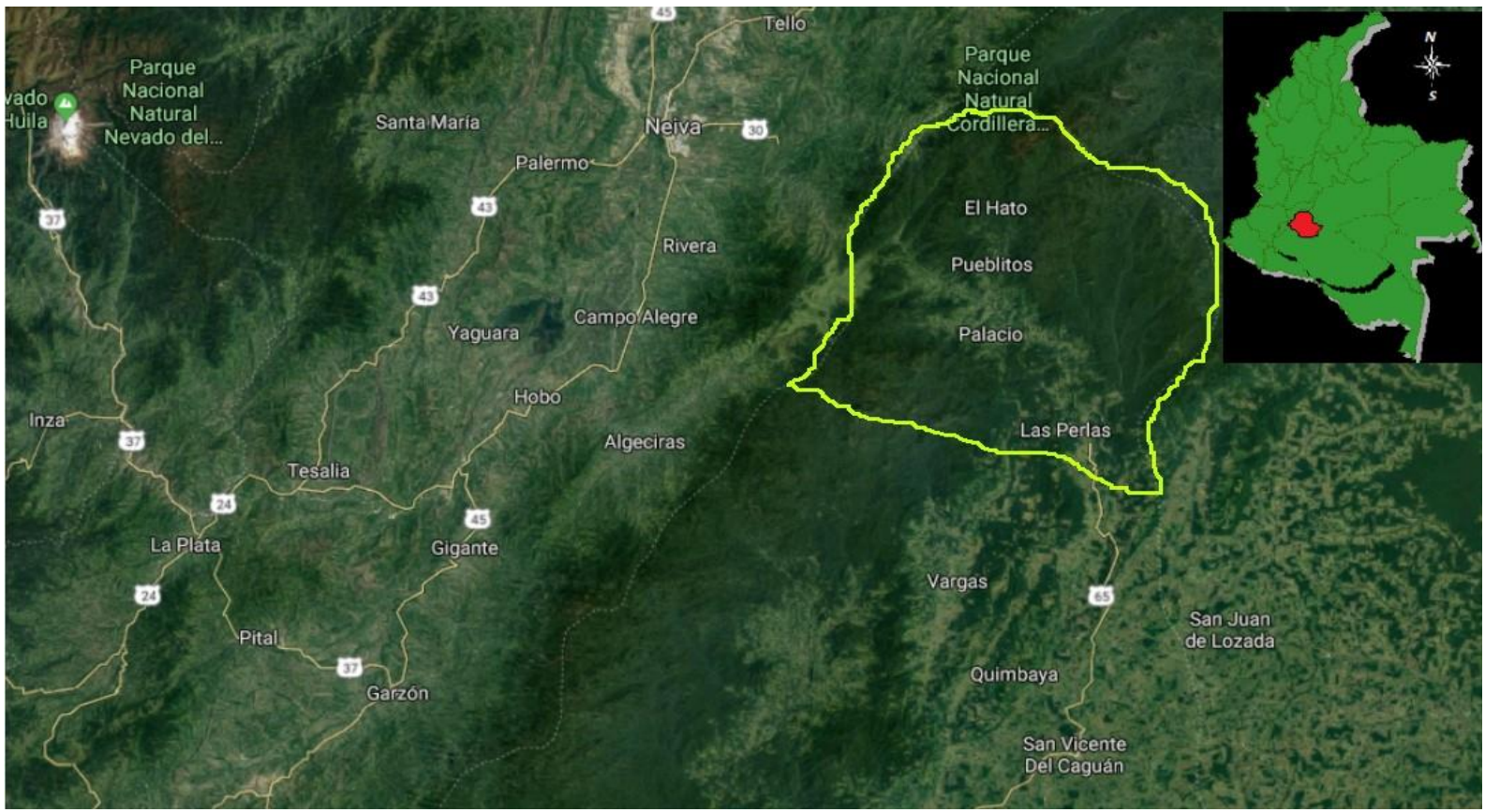

$20 \mathrm{Km}$

\section{FIGURA 1.}

ZRC El Pato-Balsillas en el departamento del Caquetá.

Fuente: elaboración propia con base en imágenes Landsat/Copernicus, Data SIO, NOOA, U.S. Navy, NGA, GEBCO y datos de Google (2017). Sistema de coordenadas WGS84. 2.64406, -74.71926 .

El municipio se caracteriza por ser un espacio conectado con una precaria infraestructura vial, con predominio de la agricultura comercial, la agroindustria y la ganadería, pobremente articulado con los mercados nacionales. La ZRC está compuesta especialmente por campesinos colonos beneficiarios de unidades agrícolas familiares (UAF) ${ }^{7}$ que actúan

7 Según el Acuerdo 202 de 2009 emitido por el Ministerio de Agricultura y Desarrollo Rural, "por el cual se adopta la metodología para definir las extensiones máximas y mínimas de baldíos adjudicables a UAF en Zonas relativamente homogéneas". Al respecto, se define la UAF como la empresa básica de producción agrícola, pecuaria, acuícola o forestal cuya extensión, conforme a las condiciones agro- de forma cooperativa y de autogestión, con cierta autonomía administrativa, como peajes, impuestos a la ganadería y control de áreas de pesca que, al tiempo, los proveen de sus servicios básicos, como agua potable y energía (Moreno Guerra, 2015).

ecológicas de la zona y con tecnología adecuada, permite a la familia campesina remunerar su trabajo y disponer de un excedente capitalizable que coadyuve a la conformación de su patrimonio. Las UAF ubicadas dentro de las zonas de reserva campesina son inembargables, imprescriptibles e inexpropiables, de conformidad con lo establecido en el artículo 63 de la Constitución Política. También reglamenta que el Incoder procederá a adquirir o expropiar las superficies que excedan las dos UAF (Acuerdo 202, Ministerio de Desarrollo Rural, diciembre de 2009). 
FIGURA 2.

Panorámica de la ZRC de El Pato-Balsillas:

la agroecología como medio de vida sostenible en El Pato-Balsillas

Fuente: archivo propio.

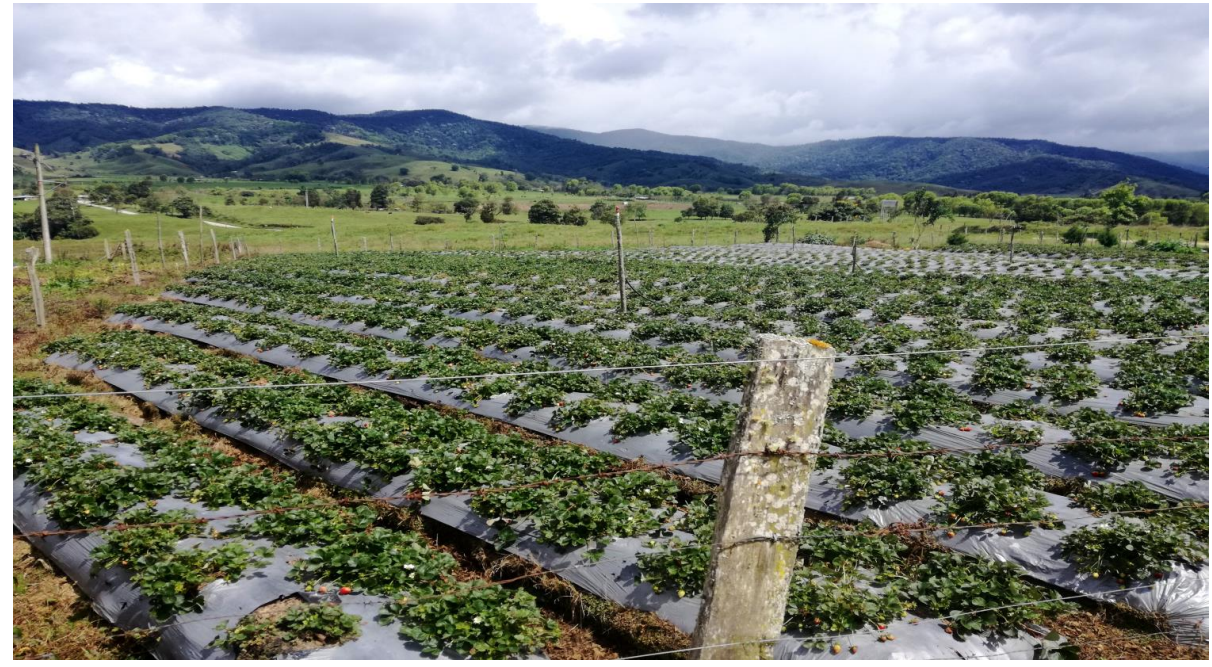

Entre todos los aspectos a destacar de la experiencia organizativa de El Pato uno de los que merece una mayor profundización es sin duda alguna el relacionado con las prácticas individuales y colectivas del ejercicio del poder local que representan las Juntas, pues a diferencia de muchas zonas rurales donde la filiación política de los integrantes de la Junta define en buena medida su identidad - Liberal, Conservadora o Comunista - en El Pato esta característica no existe, y eso no niega la filiación política de sus miembros sino que manifiesta un entendimiento de lo político donde el llamado bien común y la democracia participativa parecen ser los ejes estructurantes (p. 24).

Por otra parte, se destaca el reconocimiento de gobiernos y organismos internacionales y de una cantidad creciente de consumidores de las ventajas que conlleva la forma de organización socioeconómica de las comunidades campesinas y étnicas para la preservación del medio ambiente, que se ha manifestado, por un lado, en una mayor libertad de gestión de proyectos productivos propios y un incremento en la accesibilidad de los gobiernos de Lisseth Soto (2014): 
para que las comunidades sean las responsables de extensas áreas de conservación, producción y seguridad alimentaria. Así mismo, un creciente número de consumidores reconoce y valora la oferta de productos de mejor calidad nutricional y ecológicamente producidos.

En las dinámicas configuracionales de la ZRC de El Pato actualmente intervienen diversos actores como el Estado, mediante la alcaldía y la gobernación, con sus programas de restitución de tierras y reinserción de excombatientes a la vida civil, y las empresas privadas y multinacionales como Nestlé, la cual afecta grandes extensiones de tierra para la ganadería extensiva. También están las comunidades locales organizadas, como la Asociación Municipal de Colonos de El Pato (Amcop), y las redes de organizaciones sociales y organismos no gubernamentales nacionales, como la Fundación Picachos y el Programa de Desarrollo y Paz del Huila y Piedemonte Amazónico (PDP Huipaz), y organismos internacionales, como el Consejo Noruego para los Refugiados. En su conjunto, estas organizaciones se proponen reivindicar la importancia de la economía campesina y el aporte de los pequeños productores al desarrollo territorial y la construcción de paz territorial (Organización de las Naciones Unidas para la Alimentación y la Agricultura [FAO], 2015), en un escenario escasamente integrado con los mercados nacionales, con poca conectividad vial y de servicios, sobre los cuales se enfocan las estrategias de Reforma Rural Integral (RRI) en el marco de la implementación de los Acuerdos de La Habana.

En el acuerdo de paz, firmado recientemente en La Habana, se trazaron tareas conjuntas en entre el Gobierno nacional y la exguerrilla de las FARC, hoy convertida en la Fuerza Alternativa Revolucionaria del Común (movimiento político) para desarrollar estrategias de Reforma Rural Integral (RRI), se definen las ZRC como forma de organización de la población rural y de la economía campesina sostenible que contribuye al cierre de la frontera agrícola y la sostenibilidad ambiental. La propuesta de una Reforma Rural Integral se considera como unos de los ejes centrales del acuerdo de paz de La Habana y las ZRC aparecen como una de las formas de ordenamiento del desarrollo rural que figuran tanto en la propuesta del Gobierno nacional como en las enviadas por la Mesa de Unidad de organizaciones Agrarias (MUA). En esa línea también han propuesto la exclusión de esas zonas de los planes extractivistas y el establecimiento del derecho a la consulta previa para cualquier programa de inversión por parte de las empresas multinacionales en esos territorios. La figura de las ZRC se presenta como una estrategia de defensa de las comunidades rurales y como garantía de permanencia en el territorio, ya que asegura al campesino el derecho a la tierra al invocar el deber del Estado de promover políticas redistributivas que permitan el acceso del campesinado a la tierra en forma individual, asociativa o colectiva, así como a otros recursos productivos (Osejo, 2013). El Estado se compromete a reconocer y proteger el derecho de las comunidades a mantener, controlar y desarrollar sus conocimientos tradicionales, sus recursos genéticos y sus semillas conforme a sus modos de vida. Por último, la propuesta plantea que "el Estado reconocerá diversas formas de territorialidad campesina en áreas geográficas cuyas características agroecológicas y socioeconómicas requieran o permitan el fortalecimiento de la economía propia y el desarrollo de planes de vida de comunidades campesinas" (Proyecto de Acto Legislativo número 02 de 2018), como lo sugieren las dinámicas de configuración de las ZRC. 
El debate se ha intensificado porque, por un lado, ante la demanda de reconocimiento en los términos de la ley vigente, la Asociación de ZRC y las FARC ahora agregan la propuesta de un reconocimiento como entidades territoriales con derechos iguales de autonomía a los que hoy tienen por constitución y por ley los resguardos indígenas y los territorios colectivos de comunidades negras. Esto constituye de entrada un litigio de frontera a través del cual puedan establecerse los límites de cada asentamiento o la interculturalidad. Por otro lado, el Gobierno nacional recientemente expidió la Ley 1776 de 2016, “por la cual se crean y se desarrollan las zonas de interés de desarrollo rural, económico y social, Zidres", poniendo en juego diversos intereses, principalmente económicos, sobre las tierras baldías que reclaman los campesinos sin tierras, lo cual beneficia la entrada de grandes capitales e inversionistas a las regiones y permite la deforestación, la contaminación y el despojo (Dussán, 2017). Todo esto va en contravía de lo que hasta el momento pareciera ser un punto de encuentro del acuerdo de paz de La Habana entre las organizaciones campesinas, el Gobierno y las guerrillas frente al reconocimiento de las ZRC como alternativas de vida, que incluso resultan ajenas a las lógicas neoliberales.

El otro caso de estudio corresponde a la ZRC de El Quimbo, ubicada a una hora de la ciudad de Neiva, donde más de 30.000 campesinos fueron despojados de sus predios, correspondientes a 8.586 hectáreas de tierra productiva localizadas sobre la cuenca alta del río Magdalena, al sur del departamento del Huila, declaradas como parte de la Reserva Forestal de la Amazonia, donde más de 3.000 hectáreas de bosque y especies epífitas fueron eliminadas, poniendo en riesgo los ecosistemas vedados desde 1977 mediante la Resolución 213 vigente, expedida por el antiguo Instituto Nacional de los Recursos Naturales Renovables (Inderena) (Dussán, 2017). El primer paso para la construcción del embalse era sustraer del área de reserva forestal el $95 \%$ de las casi 9.000 hectáreas que comprende el proyecto, hecho que no ocurrió, aun teniendo la aprobación del gobierno del entonces presidente Álvaro Uribe Vélez que, por intermedio del ministro de Minas y Energía, Mauricio Cárdenas, declaró los predios como de "utilidad pública" para favorecer la multinacional Emgesa, de capital español. Por esta razón se considera un proyecto impuesto e inconsulto que motivó la organización social y la resistencia de los directamente afectados en pro de la defensa del territorio. Esta idea de ZRC resulta como alternativa a las políticas extractivistas promovidas por el Gobierno nacional, constituida de facto como resistencia al impacto generado por la obra de infraestructura, cuyos líderes reclaman el desmantelamiento del embalse, la salida de las multinacionales y el retorno de los agricultores a sus predios para la instauración de una ZRC agroalimentaria en los seis municipios (Gigante, Garzón, Tesalia, Altamira, Agrado y El Hobo) que fueron inundados (Asoquimbo, 2016). 
ZRC El Quimbo en el departamento del Huila

Fuente: elaboración propia con base en imágenes Landsat/Copernicus, Data SIO, NOOA, U.S. Navy, NGA, GEBCO, datos de Google (2017). Sistema de coordenadas WGS84: N 2.409109, S $-75.539301$.

\section{FIGURA 3.}

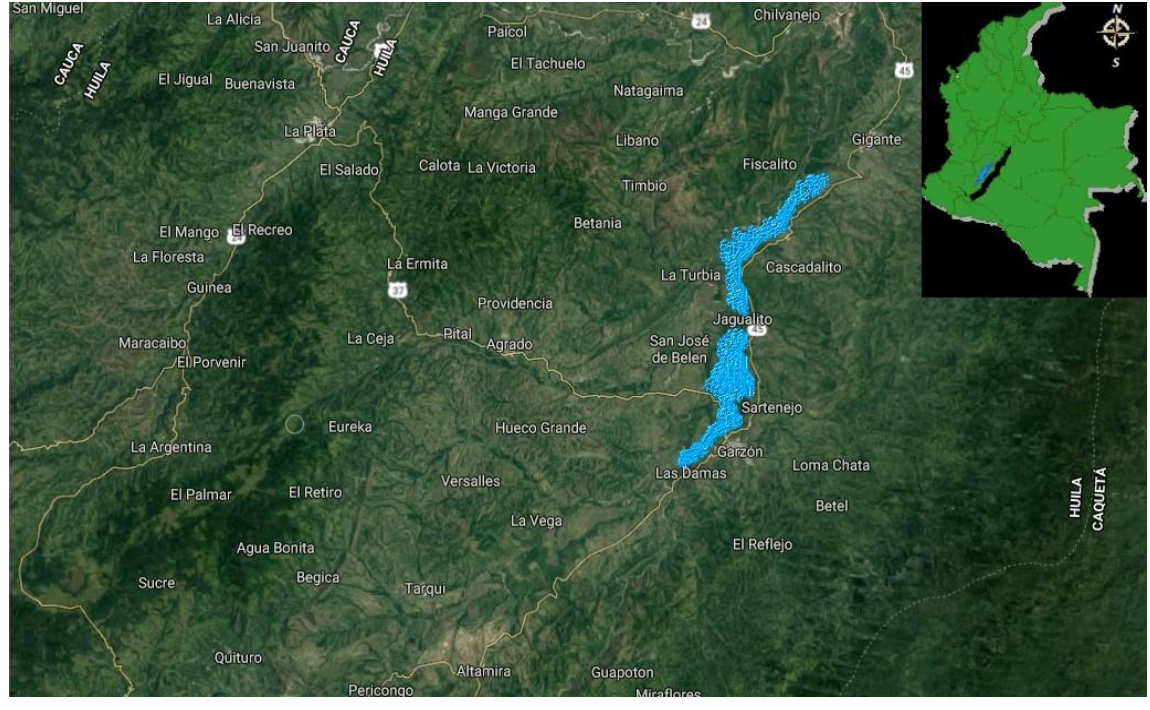

$20 \mathrm{Km}$

La complejidad de esta ZRC puede interpretarse en el sentido de la superposición de territorialidades en las cuales convergen nuevos actores en los lugares donde fueron reubicados, estableciendo nuevas relaciones urbano-rurales con nuevos vecinos locales-globales, complejidad de la organización social, heterogeneidad de los sistemas productivos, diversificación de las actividades económicas a través de pequeños negocios y prestación de servicios, y generación de ingresos, flexibilización y movilidad laboral, como ocurre en otras latitudes (Sassen, 2007; Massey, 2007). El desplazamiento de los campesinos implicó un nuevo estilo de vida que empezó a notarse en distintos y disimiles ámbitos, algunos de ellos vinculados con un espacio altamente integrado con la industria global, la tecnología y las comunicaciones, que ha sido emplazado con importante infraestructura para la industria piscícola de los municipios de Garzón y Gigante en el departamento del Huila, y que en la actualidad son los principales productores y exportadores de tilapia en Colombia hacia Estados Unidos.

En este escenario intervienen principalmente actores que, de un lado, defienden la construcción del embalse hidroeléctrico El Quimbo como una alternativa de diversificación de actividades productivas y generadoras de empleo; pero, por otra parte, están los que promueven el desmantelamiento del proyecto y el ción de una ZRC agroalimentaria. En el momento es posible observar en la zona enormes complejos de viviendas de reubicación deshabitadas, ya que muchos de los desplazados, entre propietarios y jornaleros de haciendas, fincas y parcelas, no han logrado adaptarse a sus nuevos entornos. Por ejemplo, los antiguos recolectores de tabaco de la hacienda Palacio, en el municipio de Garzón, se dedican hoy día al mototaxismo, y los pescadores, los paleros y los trabajadores de material de playa deambulan por los parques centrales de los cascos urbanos de los municipios del área de influencia de la central hidroeléctrica. La mayoría de familias despojadas pasaron de ser agricultores y trabajadores del campo a desempeñar oficios varios para los cuales no estaban adaptados. En esta zona son evidentes los altos índices de prostitución, alcoholismo, drogadicción y delincuencia, a los que se suman diversas patologías de las que antes no se hablaba, como la angustia, el estrés, la depresión y el incremento de los casos de suicidio (Dussán, 2017). retorno de campesinos a sus tierras para la instaura- 


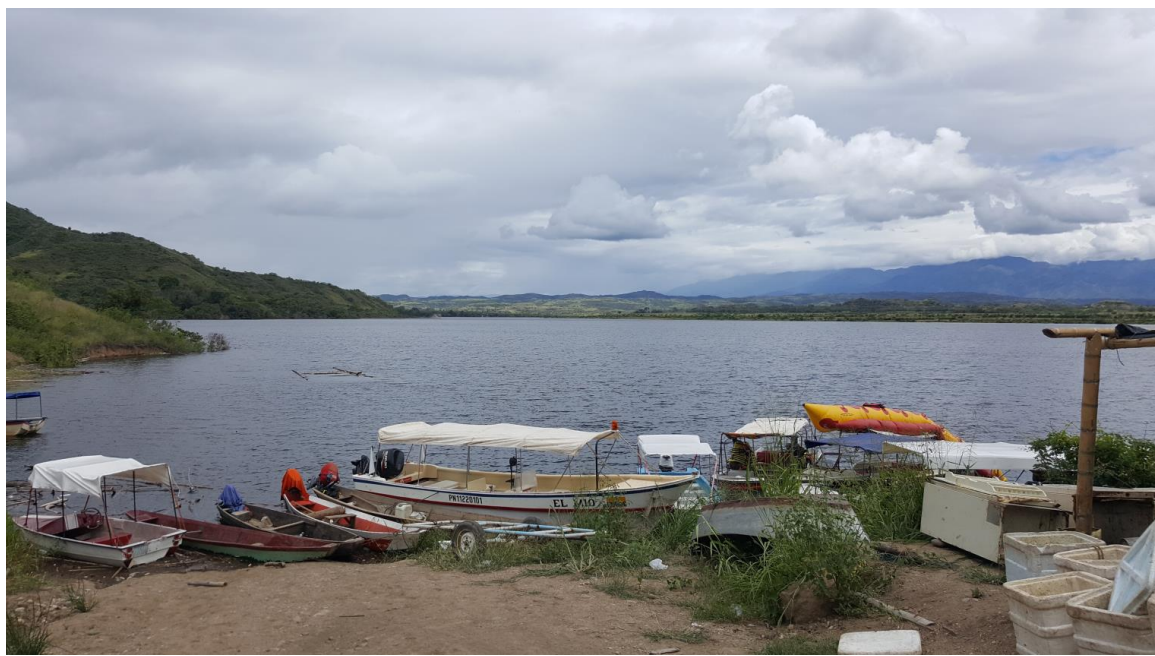

\section{FIGURA 4.}

Panorámica del embalse de El Quimbo: los desplazados del proyecto experimentan nuevas actividades productivas y oportunidades de empleo sobre áreas de cultivos inundadas Fuente: archivo propio.

Para sintetizar, al abordar las estrategias de vida en dos ZRC podemos evidenciar dinámicas disímiles, pero emparentadas respecto a las formas de valorización en el territorio, con perspectivas tanto económicas como sociales que revelan nuevas implicaciones en el estilo de vida, como es evidente en el caso de la ZRC de El Quimbo. Al respecto, Zambrano (2016) señala que son tres los aspectos en los cuales puede centrarse el análisis de las dinámicas territoriales y de la diversidad en la construcción de la singularidad de los procesos en cada $\mathrm{ZRC}$, que pueden contribuir a desplazar o hacer converger las luchas por la tierra con las luchas por el territorio en una nueva forma de estructuración territorial: el primer aspecto es que frente a la visión simétrica y homogénea de las ZRC, y a partir de una primera inspección, estas se presentan de manera diversa e impulsan movimientos diferenciados entre sí. Aun cuando existen elementos ectructurantes en las dinámicas de configuración del territorio, tanto en El Pato como en El Quimbo, los procesos de territorialidad y territorialización no son los mismos: por ejemplo, en el caso de la ZRC de El Pato la propiedad de la tierra se da en un escenario de desplazamiento, conflicto armado y campesinos sin tierra que se asentaron sobre terrenos baldíos (Carillo González, 2016), mientras que en el caso de El Quimbo los propietarios de las tierras fueron literalmente despojados de sus propiedades, algunos obligados a vender y otros expropiados porque se negaban a salir de su territorio (Dussán, 2017). Es lo que Sassen (2007) ha llamado "la acumulación por despojo", que en El Quimbo benefició al capital transnacional a través de Emgesa, empresa de propiedad italiano-española. Con esto inferimos que aunque la tierra, como elemento estructurante de la movilización campesina, siempre ha estado presente en las movilizaciones y las luchas históricas, tiene un carácter dinámico que gira en torno a la tenencia, la propiedad, el uso, el manejo y la gestión de la misma, del cual emergen diversas estrategias y medios de vida. De ahí que es necesario estudiar las ZRC en su singularidad y compararlas.

En segundo lugar, y como consecuencia de lo anterior, se considera que si bien las ZRC surgen de una misma norma y en el marco de un proceso de globalización, de modernización del campo y de procesos de paz en Colombia, debemos estudiar cómo se desarrollan y apropian socialmente y cómo entran a formar parte del ordenamiento territorial y a incidir en él. Por último, la complejidad de la estructuración territorial implica, al decir de Zambrano (2010), entender que "los cambios territoriales 
y las nuevas significaciones, al ser históricas, están disputándose la inserción en la sociedad o en los sistemas de reconocimiento y redistribución social [...] que, como el caso de las ZRC [...], son formas de participación por las que la gente opta para hacer uso de los derechos que las comunidades disponen, por lo que las representaciones territoriales en disputa, también disputan ideas de cohesión social” (p. 13).

En los dos casos presentados se puede afirmar que, más allá de la lucha por la tierra, existe la lucha por el territorio en torno al reconocimiento por la diversidad y las autonomías identitarias, en las cuales la tierra ha sido el factor estructurante de la organización social, de la resistencia, la movilización y de las dinámicas de construcción territorial que se manifiestan en la diversidad de estrategias de vida adoptadas por el campesinado.

\section{Conclusiones}

En el marco de lo geográfico, el análisis de este artículo destaca la importancia de considerar y concebir la figura de las ZRC como otra forma desde la cual las comunidades y los pobladores rurales están produciendo territorio y creando otras formas distintas a las que impone el Estado para ordenar sus espacios, construir sus propias identidades y territorios y luchar por implementar en ellos sus propios proyectos de vida. En tal sentido, la formulación de una política de reordenamiento territorial por parte del Estado que sea asumida por las comunidades genera una tensión que debe ser resuelta con la propia construcción política del territorio que las mismas poblaciones plantean y proponen de manera dialéctica, frente a esas formas estructurales del Estado que se reflejan en los marcos normativos y en la vida rural misma.
Pero esta construcción política del territorio corre pareja con el proceso de constitución de "tradiciones, formaciones e instituciones" de los distintos actores sociales y políticos, capaces de encarnar un proyecto político común (Williams, 2009). Son los actores, a través de los distintos proyectos políticos, quienes tienen la voluntad y, por consiguiente, la capacidad de producir territorio en una ZRC entendida, finalmente, como un proyecto político común. Los actores son, pues, los que crean los diferentes espacios sociales. En estricto sentido, como lo señala Laserna (1986), la ZRC debe entenderse como un gran sujeto colectivo.

Desde la perspectiva de las estrategias de vida rural, de los emplazamientos y las identidades, resulta sugerente pensar el proceso de construcción del territorio más a partir de la relación de los actores y las comunidades con su base territorial, local y regional, pero, dentro de su estrategia de construcción de contrapoderes, formulado con relación a los procesos que se dan en el ámbito nacional.

Se debe partir del reconocimiento que hay de las unidades territoriales forjadas por la historia y la geografía (elementos residuales y dominantes), que tiene una entidad sociocultural, un patrimonio y un signo de identidad de la población y merecen una estrategia diferenciada frente a los proyectos de construcción territorial. Incluso la historia del conflicto armado interno le ha dado contornos definidos a las regiones y localidades y ha demarcado gran parte de sus dinámicas sociales y políticas actuales, como ocurre con la ZRC del Caquetá. En esta dirección, los procesos de descentralización político-administrativa, de desconcentración del poder y de regionalización, no obstante las grandes dificultades que plantean, aparecen como interrogantes ante las estrategias políticas de profundización 
de la democracia, de construcción y vigorización de la sociedad civil y de sus actores, así como de la posibilidad de consolidar nuevos consensos y de generar y apoyar, sobre esta base, procesos de construcción democrática de territorios. De la misma manera, la territorialización de un nuevo espacio, como ocurrió en la ZRC de El Quimbo, permitió reactivar capacidades sociales y recursos reivindicativos en una lucha que todavía continúa.

En términos generales, el carácter emergente de los procesos de diferenciación territorial no es más que la expresión, en el plano espacial, de las características físico-bióticas del territorio y de la localización y el nivel de desarrollo de determinadas actividades económicas, de los grados de articulación socioespacial entre las distintas escalas regionales, subregionales, locales y el nivel nacional (Cuervo y Williner, 2007). Es decir, de la relación entre los espacios efectivos y los espacios difusos, de la estructura y dinámica de los grupos de población y las organizaciones sociales; del grado de atención por parte del Estado central y su capacidad de negociación frente a los niveles ínter e intra territoriales; del propio proceso de construcción y constitución de actores territoriales, representantes y representables con respecto al nivel central, pero, sobre todo, de la capacidad de construir un proyecto colectivo y de los alcances de su eventual apuesta política, punto en el cual afloran las distintas estrategias y dinámicas de los diferentes actores políticos. Citando a Harvey (2010), "la construcción de un orden social alternativo se encuentra ligada a la construcción de formas territoriales socialmente más justas, o utopías territoriales concretas" (p. 45). Los breves ejemplos, revelados por las ZRC y todavía por documentar con el paso del tiempo, nos enseñan que los caminos de las estrategias políticas y de la vida social campesina no son uniformes y que la riqueza en la diversidad nos muestra un camino hacia una política más diferenciada y menos general y homogénea. 


\section{Referencias}

Asociación Nacional de Zonas de Reserva Campesina (Anzorc). (2014). Ordenamiento ambiental, derechos campesinos: ruta para la construcción de paz. Ponencia presentada en el II Congreso Colombiano de Áreas protegidas: territorios para la vida y la paz. Julio 16 de 2014, Bogotá, Colombia.

Asociación de Afectados por el proyecto hidroeléctrico El Quimbo (Asoquimbo). (2016). Las víctimas del proyecto hidroeléctrico El Quimbo exigen a la ANLA suspensión de la licencia ambiental a Emgesa. Recuperado de http://www.quimbo. com.co/2016/11/las-victimas-del-proyecto.html.

Baribbi, A. y Spijkers, P. (2011). Campesinos, tierra y desarrollo rural. Reflexiones desde la experiencia del Tercer Laboratorio de Paz. Bogotá: Acción Social, Unión Europea. Recuperado de http://eeas.europa.eu/archives/delegations/colombia/documents/ projects/cartilla_tierra_y_desarrollo_lab_paz_iii_es.pdf.

Bauman, Z. (2008). La globalización: consecuencias humanas. México: Fondo de Cultura Económica.

Berdegué, J., Ospina, P., Favareto, A., Aguirre, F., Chiriboga, M., Escobal, J., ... Trivelli, C. (2011). Determinantes de las dinámicas de desarrollo territorial rural en América Latina. [Documento de Trabajo n. ${ }^{0}$ 101]. Santiago de Chile: Centro Latinoamericano para el Desarrollo Rural (Rimisp). Recuperado de http://www. rimisp.org/wp-content/files_mf/1366288690N101_DeterminantesdelasDTR_ BerdegueOspinaFavaretoAguirreChiribogaetal2011.pdf

Bozzano, H. (2004). Territorios reales, territorios pensados, territorios posibles. Aportes para una teoría territorial del ambiente. Buenos Aires: Editorial Espacio.

Carrillo González, S. (2016). “iJuntos, pero no revueltos!” (O de cómo se ha concertado la regulación social en medio de la guerra). El caso de la región de El Pato. San Vicente del Caguán, Colombia. 1956-2016. (Tesis de maestría) El Colegio de Michoacán, A. C., México. Recuperado de https://www.researchgate.net/ publication/308024729_Juntos_pero_no_revueltos_O_de_como_se_ha_ concertado_la_regulacion_social_en_medio_de_la_guerra_El_caso_de_la_region_ de_El_Pato_San_Vicente_del_Caguan_Colombia_1956-2016

Centro Nacional de Memoria Histórica (CNMH). (2014) "Patrones" y campesinos: tierra, poder y violencia en el Valle del Cauca (1960-2012). Bogotá: CNMH.

Cuervo, M. y Williner, A. (2007). Políticas e instituciones para el desarrollo económico territorial. Santiago de Chile: ILPES, CEPAL, Naciones Unidas.

De Saussure, F. (2003). Écrits de linguistique générale, texte établi et édité par Simon Bouquet et Rudolf Engler. París: Gallimard.

Dirven, M. (2004). El empleo rural no agrícola y la diversidad rural. Revista de la CEPAL, 83, 49-69. Recuperado de https://www.cepal.org/es/publicaciones/10963empleo-rural-agricola-la-diversidad-rural-america-latina.

Dollfus, O. (1991). Territorios andinos: reto y memoria. Lima: IFEA-IEP. 
Dussán, M. (2017). El Quimbo: extractivismo, despojo, ecocidio y resistencia. Bogotá: Torre Gráfica Limitada.

Estrada, J., Ferro Medina, J., Huffington R. y Herrera, J. (2013). Territorios campesinos, la experiencia de las zonas de reserva campesina. Bogotá: Universidad Nacional de Colombia.

Organización de las Naciones Unidas para la Alimentación y la Agricultura (FAO). (2015). Estado mundial de la agricultura y la alimentación 2015. La protección social y la agricultura: romper el ciclo de la pobreza rural. Recuperado de http://www.fao. org/3/a-i4953s.pdf.

Fals Borda, O. (1969). La crisis social y la orientación sociológica: una réplica. Aportes, $13,62-76$.

Forero, J. (2013). La eficiencia económica de los grandes, medianos y pequeños productores agrícolas colombianos. En L. Garay, F. Barberi, C. Ramírez, D. Suárez y R. Gómez, Reflexiones sobre la ruralidad y el territorio en Colombia: problemáticas y retos actuales (pp. 69-115). Bogotá: Corcas Editores SAS.

Giarracca, N. (1993). Los pequeños productores en la nueva ruralidad: procesos y debates. Ponencia presentada en el XIX Congreso de la Asociación Latinoamericana de Sociología, 30 de mayo al 4 de junio, Caracas, Venezuela.

Giddens, A. (1998). La constitución de la sociedad. Bases para la teoría de la estructuración. Buenos Aires: Amorrotu.

González, J. (1992) Espacios de exclusión, el estigma de las repúblicas independientes 1955-1965. Bogotá: CINEP.

González, J. (2004). In-Sur-Gentes, construir región desde abajo. Neiva: Universidad Surcolombiana.

Gurevich, R. (2005). Sociedades y territorios en tiempos contemporáneos: una introducción a la enseñanza de la geografía. Buenos Aires: Fondo de Cultura Económica.

Harvey, D. (2003). La condición de la posmodernidad. Investigación sobre los orígenes del cambio cultural. Buenos Aires: Amorrortu.

Harvey, D. (2010). Del espacio al lugar y de regreso. En B. Berenzon y G. Calderón (coords.), El tiempo como espacio y su imaginario (pp. 19-68). México: Ediciones UNAM.

Instituto Colombiano de Desarrollo Rural (Incoder), Instituto Latinoamericano para una Sociedad y un Derecho Alternativo (ILSA), Sindicato de Pequeños Agricultores de Cundinamarca (Sinpeagricun). (2012). Zonas de Reserva Campesina. Elementos introductorios y de debate. Bogotá: Gente Nueva.

Kay, C. (2007). Enfoques sobre el desarrollo rural en América Latina y Europa desde mediados del siglo XX. En E. Pérez (comp.), La enseñanza del desarrollo rural: enfoques y perspectivas (pp. 49-111). Bogotá: Pontificia Universidad Javeriana.

Laserna, R. (1986). Movimientos sociales regionales. Apuntes para la construcción de un campo empírico. Revista Pensamiento Iberoamericano, (10), 1-23. 
Llambí, L. y Pérez, E. (2007). Nuevas ruralidades y viejos campesinismos. Agenda para una nueva sociología rural latinoamericana. Cuadernos de Desarrollo Rural, 4(59), 37- 61. Recuperado de http://revistas.javeriana.edu.co/index.php/desarrolloRural/ article/view/1215.

Ley 160 (5 de agosto de 1994). Por medio de la cual se crea el Sistema Nacional de Reforma Agraria y Desarrollo Rural Campesino, se establece un subsidio para la adquisición de tierras, se reforma el Instituto Colombiano de la Reforma Agraria y se dictan otras disposiciones. Diario Oficial n. ${ }^{\circ} 41.479$.

Ley 1776 (29 de enero de 2016). Por la cual se crean y se desarrollan las Zonas de Interés de Desarrollo Rural, Económico y Social, Zidres.

Linck, T. (2000). El campo en la ciudad: reflexiones en torno a las ruralidades emergentes. Seminario Internacional, Pontificia Universidad Javeriana, Bogotá, Colombia. Recuperado de http://biblioteca.clacso.edu.ar/ar/libros/rjave/paneles/linck.pdf.

Linck, T. y Caron, P. (1999). Action collective et recomposition territoriale. En Actes du séminaire Dynamiques Agraires et construction social du territoire, 26-28 de abril, Montpellier, Francia (cap. 5). Toulouse : Université de Toulouse Le Mirail.

Lipietz, A. (1979). El Capital y su espacio. México: Siglo XXI.

Long, N. y Long, A. (Eds.). (1992). Battlefields of Knowledge: The Interlocking of Theory and Practice in Social Research and Development. Londres: Routledge.

López, M. (2013). Construcciones de paz en medio de la crisis cafetera: dos experiencias de desarrollo alternativo para la formulación de políticas públicas pacifistas. (Tesis doctoral). Universidad de Granada, España.

Machado, A. (1999) Reforma agraria: una ilusión que resultó un fracaso. Revista Credencial Historia, 119. Recuperado de http://www.banrepcultural.org/bibliotecavirtual/credencial-historia/numero-119/reforma-agraria-una-ilusion-que-resultoun-fracaso.

Massey, D. (2007). Geometrías del poder y la conceptualización del espacio. Conferencia dictada en la Universidad Central de Venezuela, Caracas, el 17 de setiembre.

Ministerio del Medio Ambiente (1998). Lineamientos para la política nacional de ordenamiento ambiental del territorio. Bogotá: Oficina Asesora de Ordenamiento Ambiental, Ministerio del Medio Ambiente.

Moser, C. (1998). The asset vulnerability framework: reassessing urban povety reduction strategies. World Development, 26(1), 1-19. doi: https://doi. org/10.1016/S0305-750X(97)10015-8.

Moreno Guerra, D. M. (2015). “El Estado Somos Nosotros": Prácticas organizativas comunitarias de la zona rural de San Vicente del Caguán-Caquetá, como materialización de la construcción del Estado local en Colombia. (Tesis de maestría). Departamento de Antropología, Universidad de los Andes, Colombia. Recuperado de http:// repositorio.uniandes.edu.co/xmlui/handle/1992/5823.

Nates-Cruz, B. (2007). Diccionario de relaciones interculturales: diversidad y globalización. Madrid: Editorial Complutense. 
Ocampo, J. (2014) Misión para la transformación del campo. Saldar la deuda histórica con el campo. Marco conceptual de la Misión para la Transformación del Campo. Bogotá: DNP.

Osejo, A. (2013). Zona de Reserva Campesina: política pública y estrategia para la defensa de territorios campesinos. Aportes para su reglamentación y aplicación. Recuperado de http://www.indepaz.org.co/wp-content/uploads/2013/04/Zona_de_Reserva_ Campesina_Politica_publica_y_estrategia_para_la_defensa_de_territorios_ campesinos.pdf.

Proyecto de Acto Legislativo número 02 de 2018 Senado. (2018). Por medio del cual se reconoce al campesinado como sujeto de derechos, se reconoce el derecho a la tierra y a la territorialidad campesina y se adoptan disposiciones sobre la consulta popular

Raffestin, C. (2011). Por una geografía del poder. Michoacán: El Colegio de Michoacán.

Reyes, A. (2016). La reforma rural para la paz. Bogotá: Penguin Random House.

Ruiz, M. (2015). In Search of Ordenamiento Ambiental Territorial in the Peasant Reserve Zones of Colombia. (Tesis de maestría). Syracuse, Syracuse University. Recuperado de https://surface.syr.edu/etd/292/.

Ruiz, N. y Delgado, J. (2008). Territorio y nuevas ruralidades: un recorrido teórico sobre las transformaciones de la relación campo-ciudad. Revista Eure, XXXIV(102), 77-95. Recuperado de https://scielo.conicyt.cl/scielo.php?script =sci arttext\&pid =S0250-71612008000200005.

Santos, M. (1996) La naturaleza del espacio. Técnica, razón y emoción. París: Roquepiquet.

Santos, M. (1990). Por una nueva geografía. Madrid: Espasa-Calpe.

Sassen, S. (2007). Territorio, autoridad y derechos. Buenos Aires: Editorial KATZ.

Sassen, S. (2015). Expulsiones. Buenos Aires: Editorial KATZ.

Schejtman, A. y Berdegué, J. (2004). Desarrollo territorial rural. Santiago de Chile: Centro Latinoamericano para el Desarrollo Rural (Rimisp).

Silva, D. (2016). Construcción de territorialidad desde las organizaciones campesinas en Colombia. Revista Latinoamericana Polis, 43. Recuperado de https://journals. openedition.org/polis/11786.

Soto Godoy, L. (2014). “iRetornamos para quedarnos!” Memorias subalternas y acción colectiva en la zona de reserva campesina de El Pato. San Vicente del Caguán-CaquetáColombia. (Tesis de grado). Popayán, Universidad del Cauca.

Ulloa, A. (2006) La construcción del nativo ecológico. Bogotá: ICANH.

Williams, R. (2009). Marxismo y literatura. Buenos Aires: Las Cuarenta.

Zambrano, C. (2010). Territorio, diversidad cultural y trabajo social. Revista trabajo Social 12, 9-24. Recuperado de https://revistas.unal.edu.co/index.php/tsocial/ article/view/18082.

Vol. 23 N. ${ }^{\circ} 1$

enero - junio de 2018

pp. 31-52 
Zambrano, C. (2013). Memoria construens. Dinámicas territoriales y comunidades emergentes, México y Colombia. Ponencia presentada en el XII Seminario Internacional sobre Territorio y Cultura, San Agustín, Huila, Colombia.

Zambrano, C. (2016). El hecho territorial, zonas de reserva campesina y cultura de paz. Ponencia presentada en taller de gestión, Máster Cultura de Paz, Universidad de Cádiz. 